\title{
Human nature \& the open society
}

\author{
Thom Scott-Phillips \\ Department of Cognitive Science, Central European University
}

To appear in: C. Royer \& L. Matei (Eds.), Open Society Unresolved: The Contemporary Relevance of a Contested Idea. CEU Press.

\begin{abstract}
How do we most effectively live together? The goal of this paper is to help reinvigorate the concept of open society, by presenting an updated, summary model of the panhuman cognitive phenotype ('human nature'), and summarizing its most important implications for how to think about collective governance. I describe the human mind as a fundamentally social mind, geared towards the specific adaptive challenges of an ultrasocial existence among both kin and non-kin. In consequence, there are deep evolutionary and cognitive reasons why reason and decision making are especially effective in dialogue and interaction within relatively small groups. Relevant and revealing real-world examples include jury discussion in criminal trials, editing on Wikipedia, and the 2018 Irish referendum on abortion. The essential challenge for large and complex societies is how to recapitulate these dynamics more broadly. The traditional liberal demands of open society meet this essential challenge only in part. Distinguishing open engagement within and between institutions, I argue that we should research, teach and advocate for more overtly interactive approaches to governance, including in particular deliberative approaches to law making. This will make more effective use of distinctive human cognitive capacities. It will also provide new responses to legitimate conservative worries about the possible excesses of open society.
\end{abstract}

Keywords open society; Popper; cognitive science; reasoning; collective intelligence; human nature; evolutionary psychology; egalitarianism

Word count 5,400 
Developed in the specific historical context of two World Wars, the Holocaust and the rise of totalitarian regimes, the notion of open society is an attempt to answer the question of how we can most effectively live together in large and modern environments. Although hard to pin down precisely, open society can be fairly characterized by a commitment to the rule of law, freedom of association and debate, free and fair elections, and the protection of individuals and minority groups. Henri Bergson, who first coined the expression, and Karl Popper, who become its most influential proponent, together offered a mix of moral, political, psychological, epistemic and normative arguments in favour of these ideals (Bergson, 1935; Popper, 1952). Like all political philosophy, these arguments necessarily depend on assumptions_-sometimes hidden and unexamined-about 'human nature' (admittedly an imperfect term). Popper, for instance, argued in favour of his model of open society based in part on his analysis of humans as problem solvers, which he justified with reference to the theory of natural selection and what he believed it implied for humanity (Stokes, 1995; 2016).

Here I present an updated model of the panhuman cognitive phenotype ('human nature') based on the findings of modern evolutionary, cognitive and anthropological science; and I summarise what I believe these findings imply for how to think about collective governance. Here, 'collective' can be understood at any scale from, say, a local housing organisation to, at the other extreme, the resolution of truly global problems such as climate change and international tax avoidance. In short, I aim to address the question, what does our contemporary understanding of human nature suggest about how to most effectively live together in large and complex societies? I shall describe the human mind as a primarily social mind, far more finely tuned to the challenges of living together than we understood even two decades ago; and I shall conclude that we should embrace far more overtly open approaches to governance. Standard liberal demands made in the name of open society do not go far enough.

\section{Human minds are social minds}

Governance and decision making depend upon harnessing human capacities for reason and reasoning; yet there seem to be two contradictory views about the nature of human reason. On the one hand, the intuitive and historically influential idea is that reason functions to help each of us get closer to the truth and hence make better decisions. This is often called Cartesianism, following René Descartes' arguments for the privileged status of reason as a source of knowledge and hence for the distinctiveness of humans as a species. 
On the other hand, everybody knows that we're prone to biases and logical fallacies that are in fact formally quite simple. The most well-known example is confirmation bias: the tendency to search for, interpret, favor, and recall information in a way that confirms or supports your prior beliefs, rather than evaluating information on its own objective merits. As author and comedian Jon Ronson put it, "Ever since I first learned about confirmation bias I've been seeing it everywhere". There are dozens of logical fallacies like this, documented in many laboratory studies and with substantial real-world consequences. This raises the paradox, if the function of reason is epistemic and objective, then why are we often poor at it, including when it matters to be right? If reason is so basic to what makes us distinctive as a species, its recurrent bugs and flaws are hard to explain.

The apparent contradiction is resolved by dropping the assumption that the function of reason is epistemic, and replacing it with an interactive perspective (Mercier \& Sperber, 2017). Put simply, reason is not individual and objective, it is social and subjective. Reasoning with yourself is certainly possible and useful (as Descartes exemplified), but it is an acquired skill akin to, say, lifting heavy weights. Particular individuals can become highly competent but they also have off-days, they are prone to regress if the skill is not practiced, and strong institutional support-schooling-is necessary if the skill is to become widespread and stable in the population at large. Pushing this analogy further, reasoning with others is like walking. Like lifting weights, walking entails moving something heavy (your own body), but in this case the task is easy and natural because our bodies are built to do this. Correspondingly, just as the science of anatomy has revealed how our bodies have features specialized for the task of walkingmuscles, bones, joints, and their particular designs-the science of thinking and reason has revealed how adept we are at reasoning when the target is other people, and how our minds have many features specialized for the tasks of arguing and persuading, and for critiquing what others say. This is why two heads are better than one.

Many experimental studies show the consequences of these cognitive dispositions and skills. Crowds are wise, collectives are intelligent, discussion augments utilitarian outcomes, and a diversity of perspectives enhances group decision making (e.g. Page, 2008; Bahrami et al., 2010; 2012; Navajas et al., 2018; Shi et al., 2019; O’Malley et al., 2020; Keshmirian et al., 2022; Mercier \& Claidière, in press; inter alia). This happens, fundamentally, because interaction and discourse 'go with the grain' of how panhuman capacities of reason and thinking actually work (Mercier \& Landemore, 2012). The conclusions reached through interaction are more likely to balance the interests of all 
parties, relative to other modes of group decision making, not just because all voices can be represented, important as that is, but because interaction ensures critique from people who are not already positively invested in an argument or point-of-view. This does not mean that everybody agrees, of course, but it does mean that to achieve their own goals in interaction, people have to develop and present good arguments and counter-arguments, and they have to be skeptically minded towards what others say. These demands help guide open discussion towards truths, equitable outcomes and wise decisions. These collective goods are epistemic by-products of individuals acting in their own interests in communication.

Adversarial systems of legal decision making provide a real-world example of these dynamics in action. Argumentation and deliberation occur at two distinct stages. First, legal teams each make their own best possible case, and they critique each other's. Their professional duty is not to present their own individually-reasoned analysis, but rather the best possible case for their own side and the best possible critique of the other. Second, a randomly selected jury debates the relative merits of the two sides. These juries are large enough to have some diversity of perspectives, but small enough that genuine interaction and debate can take place. In short, both stages of legal decision making are open and adversarial, and this in turn facilitates effective decision making. This system is proof-ofconcept for how institutional design can recapitulate conditions of openness and hence harness human reason for an important social purpose-criminal justice-with significant levels of success and common consent. The film 12 Angry Men idealizes and simplifies this dynamic but nevertheless make graphic this essential truth (Hans, 2007).

This interactive perspective aligns with a broader trend in the cognitive and evolutionary sciences, in which almost all the most distinctive features of human minds are explained as adaptations to the challenges of living together. Compare humans with, say, orangutans. ${ }^{1}$ As great apes, orangutans share a great deal of DNA with humans, but unlike us they live rather solitary lives, not much and not often interacting with others (except for mating and, for females, raising offspring). From an evolutionary perspective this lifestyle has both advantages and disadvantages. The costs of group living are avoided: no disease transmission, no conflict, no competition for food. (What bliss!) But there are benefits to group living too, such as collective foraging, win-win cooperation and group protection against the risks of predation; and orangutans have none of this either. Middle-ground strategies are possible (chimpanzees, gorillas), but as species humans and

1 Thank you to Coralie Chevalier for highlighting this contrast to me. 
orangutans have made, you can say, almost opposite ecological choices. Orangutans live somewhat solitary lives and their bodies and minds have evolved to fit that mode of living. Humans, in very stark contrast, have evolved to live an intensely social existence, in groups that are long-lasting, loosely-defined and comprised of both kin and non-kin. To be clear, the point here is not the trite observation that humans are sociable, true as that is. The point is that, just as the human skeleton is specifically adapted for the possibilities and the demands of bipedal locomotion, the human mind is specifically adapted for the possibilities, and also the risks and the dangers, of an intensely social existence.

One important implication of this 'social minds' perspective is what it suggests about human 'rationality'. For most of human evolutionary history, the likelihood of repeated interactions has been high: meeting once suggests you will meet again. Most interactions have a past and most are likely to have a future. This social ecology generates a delicate balance of both competition and cooperation, and substantial evolutionary pressure for capacities and behaviours that make the most of this mix (Humphrey, 1976; Frith, 2007; Barrett et al., 2010; Barclay, 2013; Krasnow et al., 2013; Tomasello, 2014; Baumard, 2016; Ho et al., 2017; Engelmann \& Tomasello, 2019; McCullough, 2020; Pietraszewski, 2020; Williams, 2021; Heintz \& Scott-Phillips, in press; inter alia). The capacities include many obviously social phenomena, such as moral dispositions, persistent self-monitoring, distinctive forms of communication, an awareness of potential opportunities to exploit others, a fine-grained concern for reputation, and so on; but also cognitive capacities that on first blush do not appear to serve social functions at all. Reasoning is one example (see above); our memories of past events, and maybe even consciousness, might be others (Graziano, 2013; Mahr \& Csibra, 2018). Under conditions of ordinary social interaction, all these cognitive capacities perform in broadly optimal, or 'rational' ways.

Humans are not rational the mode of Popper or Descartes, geared towards logic, truth and problem solving. Humans can do these things but they are not the essential functions of mind. Nor are humans rational in the mode of Homo economicus, geared towards utility calculus. What the modern sciences of the mind have revealed is that humans are rational in the mode of, for instance, Jürgen Habermas (e.g. Habermas, 1984), geared towards effectiveness in repeated interpersonal engagement with other humans.

\section{Minimal conditions of open engagement}


Here is a representative list of some 'minimal' descriptive features of ordinary social interaction. Imagine, if you wish, a large-ish gathering of acquaintances or some other occasion where most people know who most others are, even if they don't necessarily know each other well. Open access. People can enter and leave conversations at will, subject to norms of politeness. Free participation. People can start to speak to anybody else. At the same time, no one is forced to speak. Listener choice. People can choose to listen to anybody else, and they can change who they are listening to at any time. They cannot listen to multiple speakers at the same time. Transparency. People can see who talks to who, and establish the relevant speaker-listener relations. They may not be privy to the details of what is said, but the existence and manner of conversations is visible. Reputational effects. Individuals can gain or lose reputations as worthwhile communicators. Reputations affect whether and how others engage. There are also second- and higher-order reputational effects: individuals can discuss others' reputations, and by doing so they can lose or gain reputations themselves.

Of course, all of these features are matters of more-or-less rather than yes-no. In different social settings they can be more or less present, and some can be more present than others; but broadly speaking, in a social ecology of recurrent meetings with many of the same individuals, the above features tend to present to some substantial degree. People can come and go, they can talk and they can listen, they can see who is talking to who, and the reputational consequences of bad faith engagement are potentially serious. To a first approximation, these are the social conditions in which the human mind evolved.

These conditions have, in turn, several effects that facilitate good faith ('open') debate and engagement with others (Speikermann, 2020). These effects echo many of the demands and characterisatics of open society and associated concepts, such as 'civil society' ,'public sphere' and the 'marketplace of ideas'. First, the above listed features expose individuals to a diversity of information and perspectives. People are exposed to views they cannot choose in advance, and which include perspectives that differ from their own. Second, these features facilitate expressive opportunity for all. Everybody has the opportunity, in principle, to have their views heard. Third, they provide transparency of deliberation and discussion. Everybody is able to observe conversations between others, witnessing who talks to who. Fourth, ordinary social interaction enables the creation of common knowledge. Public announcement is possible; and, crucially, not only do all individuals hear public announcements, they observe each other hearing at the same time. Fifth, these features ensure a degree of accountability. So long as there is real probability of future interaction on 
similar terms, good faith engagement is incentivized. Sixth, interaction provides some insurance against fallibility. People will always make individual mistakes of reason and thought, but they will be exposed to counter-arguments. And of course, these features all support, reinforce and to some extent depend on one another.

The prediction that follows is that if minimal features of ordinary social interaction ((a)-(e)) are maintained to some sufficiently high degree, that will generate conditions of open engagement ((1)-(7)) which will in turn lead to the effective use of human reason and the accepted resolution of contested issues.

Above I gave the real-world example of juries in criminal trials. Online discourse provides another example and a revealing comparison. There are substantial potential upsides to social media-in particular, people are exposed to a far larger diversity of views than they otherwise would be-but also major downsides. In many domains, such as on Facebook and Twitter, all five of the minimal features summarized above are subject to dilution, one way or another. Users are often not free to enter and leave conversations at will. They are able to communicate with all others at will. Users usually cannot see with full transparency who talks to who, because some conversations are private and because public conversations are simply too numerous. By virtue of large audience bases, some users have far greater influence and power over discourse than do others. And reputational effects can be inconsequential in a number of ways: because users can be anonymous, because many infractions are barely visible, and because interactions are often one-shot or likely to be so. These compromises are all understandable given the nature of the technology, but in any case there is a danger that self-interest can become less aligned with good faith engagement (Speikermann, 2020). Discourse ethics can become less incentivized, discourse can become toxic, and power dynamics can have outsized effects: all with the net effect that cognitive capacities of deliberation and reason are not put to effective use. The revealing comparison is Wikipedia. Here there are established, standard practices of discourse that govern the process by which articles are created and edited. Crucially, these practices adhere closely to the minimal features of open engagement I summarized above (Hansen et al., 2009; Firer-Blaess, 2011). I suggest it is not a coincidence that Wikipedia has a relatively good reputation for veracity and authority. To be fully explicit, I am suggesting a causality. The recapitulation of minimal features of ordinary interaction generates a discourse ethics within Wikipedia which, aside from being more pleasant in and of itself, also makes more effective use of reason and critique. This leads in turn to more accuracy and greater balance. 
There are parallels here with the making and unmaking of egalitarian society. One of the most intriguing things learned in 150 years of anthropological fieldwork is that small and isolated communities tend to have levels and forms of egalitarianism that surprise modern eyes (e.g. Cashdan, 1980; Woodburn, 1982; Wiessner, 2002; Boehm, 2009; Borgerhoff Mulder et al., 2009). There is, commonly, collective decision-making; a relative absence of resource inequality; little coercive political authority; widespread intolerance of unkindness; a pervasive ethos of affiliation extending beyond immediate kin; and an absence of dominance based on strength and other physical characteristics. (The story is of course not quite as simple as this summary, but this is correct to a first approximation.) Why so? The fast and easy explanation is that humans are somehow 'naturally' or 'innately' egalitarian, and that large and modern societies have corrupted us (e.g. Bregman, 2019; see e.g. Hallpike, 2020; Buckner, 2020 for critical reviews). The more nuanced and astute conclusion is that when groups are small and many people know your name, then the greatest individual rewards come from attending to local norms of how to behave, maintaining your reputation, and valuing group harmony above all (Singh et al., 2017; von Rueden, 2020, Hooper et al., 2021). Put simply, fairness and egalitarianism can overlap with self-interest, and when they do then the chances of social harmony are increased, sometimes dramatically so. What I am suggesting is that what is true of egalitarianism is also likely to be true of good faith in discourse. It can be incentivized and disincentivized, depending on the social ecology.

The challenge for large and complex societies is that minimal features of open engagement are very easily compromised. In fact openness is compromised as soon as two people hold a conversation in private, and that is obviously only the thin end of the wedge. As soon as groups become large and decisions more complex, some dilution of the ideals of open discourse becomes both necessary and inevitable. In sizeable groups, effective decision making demands some form of group organisation, making fully open discourse impossible in practice. It is no longer straightforward to enter and leave conversations at will; people no longer have fully free reign to speak to or listen to whoever they wish; people can no longer see who speaks to who; and so on. With these conditions comes the risk that good faith engagement is no longer incentivized. To put the point in paradoxical and challenging form, open engagement may be most effective when the community is relatively closed. This is the essential challenge for large and complex societies. 


\section{Open engagement within \& between institutions}

What models of governance create the most effective epistemological and normative frame for large, complex, modern societies? Popper's answer mirrored his philosophy of science, according to which hypotheses that are falsified are let go, those that resist falsification remain, and in such ways does scientific knowledge progress. This is in effect a Cartesian approach to scientific rationality, and Popper argued that open society can do a similar job for power and governance. "The fundamental problem of a rational political theory... can be formulated as follows: how is the state to be constituted so that bad rulers can be got rid of without bloodshed, without violence?". Popper's answer was, in effect, falsificationism in the domain of power: "government can be dismissed by a majority vote" (Popper, 1988). Following this logic to its conclusion, he argued in favour of twoparty systems over proportional representation, on the grounds that only two-party systems provide decisive rejections, just as only compelling experiments provide decisive falsifications (ibid.). Revealingly, Popper also coined the expression 'conspiracy theory' (Runciman, 2018). Conspiracies are ancient, of course: Popper's novelty was to add the word theory, a clear indication of the link he saw between the domains of science and politics.

Yet while important, this focus on Cartesian rationality is not sufficient as a description how science and politics actually work. Many scientists and philosophers of science have pointed out that very little science is strictly falsificationist. In particular, when hypotheses appear to be falsified scientists often do not to reject them outright, but instead explore and articulate further, ad hoc arguments and additional theories, in order to accommodate the discrepancy; and they are often right to do so. The same basic dynamics operate in democracies: elected representatives adapt when their stated values and policy positions are challenged by events. They too respond with new arguments and assertions. So in both domains counterevidence is most commonly met not with supposed ideal of falsification, but with counter-counter-argument; and what keeps people in check is not the systematic application of any particular method, but rather the collective judgement of the relevant community (on the role of community in science see e.g. Ziman, 1968; Barnes et al., 1996; Longino, 2001; Pigliucci \& Boudry, 2013).

To be fully clear, I'm not trying to suggest that scientists have the same motivations and ethics as politicians. What I'm pointing out is the similarity in praxis. There are clearly important differences between these two spheres of human activity (Weber, 2004), but one thing they share is that when ideas are challenged neither politicians nor scientists reason 
in a purely Socratic way. Rather, they reason argumentatively, as we should expect given the ultra-social nature of human cognition (see above). This is especially so in the human sciences, where predictions can rarely be made at a level of precision that would facilitate a strictly falsificationist approach (unlike, for instance, physics; see Meehl, 1967). So Popper's model for the open society misleads in the same way that his philosophy of science does: both are too much predicated on a model of the mind as a Cartesian tool of analytical logic and problem solving. But as I said above, this is not the natural mode of human rationality.

The most effective epistemological and normative frames for governance will be those that harness the social rationality for which our minds are finely equipped. More specifically, we should endevour to recapitulate at the level of institutions the conditions of open engagement that we already know generate good faith engagement in the resolution of contested issues at the level of individuals (see e.g. Szegőfi \& Heintz, in press). If this is possible, it should in turn generate the positive social effects of good faith engagement. Contemporary advocates of open society, following Popper, sometimes place special emphasis on the importance of inculcating a critical frame of mind among the population at large. This is a desirable ideal and I certainly do not discourage it, but it is less aligned with the dispositions and distinctive capacities of the human mind than the more interactive perspective that I am advocating here.

The standard demands of open society can be read as demands for minimal conditions of open engagement between institutions of governance and power:

"Power checks power... Parliamentary democracy forces executive authority to justify its measures before the adversarial scrutiny of a parliament. Judges bring the critical epistemology of law to the review of administrative and legal decisions. A free media referees the battle over public choice with a complex epistemology of scrutiny, driven by skepticism, scandal mongering, and profit seeking. Universities play their role in subjecting public claims to peer-reviewed research. These institutions... [together] create the epistemological frame in which a free society struggles its way towards the knowledge it needs, or the closure on debate it must accept, in order to chart its collective course into the future. This is how an open society actually operates." (Ignatieff, 2018, p.7)

So open societies, as traditionally conceived, entail a degree of interaction between institutions that have the effect-so the theory goes-of recapitulating minimal conditions 
of repeated ordinary interactions, and hence facilitating the positive effects of debate, argument and reputation.

Habermas' notion of the 'public sphere', and its potential role in governance, can be read as an extended version of this between-institution approach. Building on the insight that humans are highly competent, or 'rational', with respect to ordinary social interaction, and looking for ways to empower the demos, Habermas advocated in favour of deliberative approaches to governance. In particular he argued for the development of a public sphere on a level with, and in deliberative dialogue with, the public institutions of an open society (Habermas, 1989). One repeated criticism of this approach has been that, even with the best will and intent, the public sphere cannot perform this role in actuality (e.g. Tully, 2012; Landemore, 2020). Without any formal powerbase or institional structure, the public sphere is not able to take part in genuinely reciprocal dialogue with the formal institutions of modern nation states; and without that foundation, the collective benefits of sincere deliberation cannot accrue.

Another means by which to harness the epistemic, normative and emancipatory benefits of deliberation may be to focus not only on interaction not between institutions, but also within them. One important source of inspiration here is Elenor Ostrom's Nobel prize winning empirical work on the principles that best guide governance of the commons, which include in particular defined space for open discussion (Ostrom, 1990). More recently, Citizens Assemblies and other forms of deliberative mini-publics have been given an active role within institutions of law making and policy, with substantial real-world impact. These are jury-like bodies of randomly selected citizens, sufficiently diverse to be representative of the demos at large but also small enough in number enough to enable careful, open and sincere discussion (Bächtiger et al., 2018).

One well-known and successful example is the 2018 Irish referendum on the legalisation of abortion. The referendum was made possible by a preceding Citizens' Assembly in which 100 randomly-chosen citizens (stratified for region, gender and age) met over the course of successive weekends to hear from relevant experts and deliberate how the abortion issue should be addressed. Direct comparison between these deliberations and corresponding debates in more traditional domains of political discourse (parliament, media) reveals the Citizens' Assembly to have had the deeper and more sophisticated discussion, with better grasp of the subject matter (Suiter et al., in press). This is akin to the other real-world examples mentioned above: juries in criminal trials, and the comparison between Facebook and Wikipedia. Each case shows how minimal 
conditions of genuine open engagement make it possible for deliberation and debate to take place in conditions of broadly good faith, and hence to make more effective use of human capacities for reason and argument. (That is not to say that all participants will agree on all issues, of course.) In the case of the Irish abortion referendum, the deliberative context allowed the vote to take place in conditions of broadly common consent, and for its result to be enacted without unnecessary tearing at the fabric of Irish society (Suiter, 2018).

This within-institutions approach can-and, in my view, should-be pushed much further. Taken to its logical conclusion, open engagement within institutions of governance would not complement representative democracy, but replace it. This is the essential idea of 'open democracy': to use public deliberation at all levels of government and governance, via the systematic use of deliberative mini-publics, selected at random and frequently rotated (Landemore, 2013; 2020; van Reybrouck, 2016). This overtly and radically open approach to governance is in contrast to technocracy, epistocracy and other forms of rule by expert, which are sometimes advanced as possible solutions to the shortcomings of representative democracy, but which are necessarily more closed and less democractic forms of decision making (Brennan \& Landemore, 2021).

There are many types of argument in favour of this overtly and radically open approach (Dryzek et al., 2019). One is emancipatory: if democracy is rule by the demos, then should the demos should not have some entitlement to rule? A second type of argument is that it would circumvent the strategic incentives that impact, often in very substantial ways (and sometimes in fradulent ways) on representatives planning to stand for election and re-election. There are no such incentives if there is both sortition and rotation in the appointment of law makers. A third type of argument is epistemic and normative. Put simply, open democracy may be simply a superior method of law-making. Empowering all members of the demos equally, giving them all equal right of access to the deliberations that shape law and policy, may be the most effective means by which to resolve shared problems.

What I am suggesting is that the findings of cognitive science, anthropology and other fields studying 'human nature' reinforce all these arguments, by describing the deep evolutionary and cognitive reasons why deliberative approaches are especially effective. These fields have revealed the depths and extent of human social competence and rationality, and the conditions in which that competence is best exploited for the common good. 
I know it is not realistic to believe our present seats of power will vote themselves out of existence anytime soon. Nor do not believe that voters familar with present modes of democracy would all be at ease with a shift from voting to deliberation, on the abstract grounds that this would be a supposedly more democratic system. However, I do think the in-principle argument for these actions is compelling: that this is a fairer and also just better way to acheive desirable features of decision making bodies, such as legitimacy, accountability and effectiveness. At the very least, deliberative mini-publics should be studied, discussed, advocated for and indeed put to use far more commonly and in far more wide reaching ways than at present (Dryzek et al., 2019). This would allow incremental progress, by enriching our understanding of when and how deliberation is especially effective, and by advertising its potential to the public at large.

This far greater openness in governance might, furthermore, provide a compelling response to reasonable conservative concerns. The essential conservative worry is that advocates of open society mistake a rare historical acheivement-social conditions in which freedom of association and opinion are secure-for the default nature of humanity (e.g. Scruton, 1980; Oakeshott, 1991; Fawcett, 2020). These freedoms are in fact dependent on secular law and, on conservative analyses, some shared identity provided by neighbourhood, language, culture and history. A society that loosens those ties too freely risks undermining itself, by unwittingly placing into danger the tacit forms of accountability and trust that bind people and hence secure good faith engagement in the resolution of contested issues. "Conservatism is not against openness and change; it is concerned with the conditions that must be kept in place if those things are to be possible" (Scruton, 2018, p.46). I suggest that in addition to its various epistemic and other decisionmaking benefits, deliberation and open democracy address this worry by proxy. In addition to its effectiveness as a means of collective governance, open discussion can also renew and rejuvinate the fragile community relations that conservatives so value. Citizens who have taken part in deliberative mini-publics often reflect that the human engagement factor allowed them to see and understand perspectives that they otherwise would not have, even with the best will and the full availability of relevant facts. Put simply, the social ties that bind people, which are inevitably loosened in large and complex societies, can be continually retightened by engagement with other members of the demos in the serious act of open governance.

\section{Conclusion}


A great deal of thinking and argument about possible links between human nature and the structure of society, from Plato's Republic onwards, describes desired outcomes. What I am advocating for here is instead a type of process, ${ }^{2}$ in which randomly chosen members of a community deliberate on what laws and social structures are most suitable for them. This process is more open even than traditional demands made in the name of open society: more open in terms of the process of law making, and more open in terms of who is granted power. I am suggesting, moreover, that this demand for greater openness should be valued not just on moral and emancipatory grounds, but on practical grounds too. Put simply, open discussion works. It facilitates the most effective use of distinctly human cognitive skill. It should be harnessed at all levels of governance and collective decision making.

2 Thank you to Daniel Nettle for pointing out to me this contrast between outcome and process. 


\section{Acknowledgements}

I presented an early version of this paper at the online conference, 'Forget Open Society? Critical Conversations on a Contested Concept', which helped me to develop the ideas. Several people provided me with useful comments on subsequent drafts: thank you in particular to Réka Blazsek, Stefaan Blancke, Daniel Nettle, Christof Royer, Dan Sperber and the Behaviour Group at the Centre for Philosophy of Natural \& Social Science, London School of Economics.

\section{Funding statement}

TSP was financially supported by the European Research Council, under the European Union's Seventh Framework Programme (FP7/2007-2013)/ERC grant agreement no. 609819 (Somics project).

\section{References}

Bahrami, B., Olsen, K., Bang, D., Roepstorff, A., Rees, G., \& Frith, C. (2012). Together, slowly but surely: The role of social interaction and feedback on the build-up of benefit in collective decision-making. Journal of Experimental Psychology: Human Perception and Performance, 38(1), 3-8.

Bahrami, B., Olsen, K., Latham, P. E., Roepstorff, A., Rees, G., \& Frith, C. D. (2010). Optimally interacting minds. Science, 329(5995), 1081-1085.

Barclay, P. (2013). Strategies for cooperation in biological markets, especially for humans. Evolution E Human Behavior, 34(3), 164-175.

Barnes, B., Bloor, D., Henry, J. (1996). Scientific Knowledge: A Sociological Analysis. UCP.

Barrett, H. C., Cosmides, L., \& Tooby, J. (2010). Coevolution of cooperation, causal cognition and mindreading. Communicative $\mathcal{E}$ Integrative Biology, 3(6), 522-524.

Baumard, N. (2016). The Origins of Fairness: How Evolution Explains Our Moral Nature. OUP.

Bächtiger, A., Dryzek, J. S., Mansbridge, J., \& Warren, M. (Eds.) (2018). The Oxford Handbook of Deliberative Democracy. OUP.

Bergson, H. (1935). The Two Sources of Morality E Religion. Macmillan.

Boehm, C. (2009). Hierarchy in the Forest: The Evolution of Egalitarian Behavior. HUP.

Borgerhoff Mulder, M., et al. (26 authors) (2009). Intergenerational wealth transmission and the dynamics of inequality in small-scale societies. Science, 326, 682-688.

Bregman, R. (2019). HumanKind: A Hopeful History. Bloomsbury.

Brennan, J., \& Landemore, H. (2021). Debating Democracy: Do We Need More Or Less? OUP. 
Buckner, W. (2020). Book review: HumanKind by Rutger Bregman (blogpost).

Cashdan, E. A. (1980). Egalitarianism among hunters and gatherers. American Anthropologist, 82(1), 116-120.

Dryzek, J. S., Bächtiger, A., Chambers, S., Cohen, J., Druckman, J. N., Felicetti, A., Fishkin, J. S, Farrell, D. M., Fung, A., Gutmann, A., Landemore, H., Mansbridge, J., Marien, S., Neblo, M. A., Niemeyer, S., Setälä, M., Slothuus, R., Suiter, J., Thompson, D., \& Warren, M. E. (2019). The crisis of democracy and the science of deliberation. Science, 363(6432), 1144-1146.

Engelmann, J. M., \& Tomasello, M. (2019). Children's sense of fairness as equal respect. Trends in Cognitive Sciences, 23(6), 454-463.

Fawcett, E. (2020). Conservatism: The Fight for a Tradition. PUP.

Firer-Blaess, S. (2011). Wikipedia: Example for a future electronic democracy? Decision, discipline and discourse in the collaborative encyclopaedia. Studies in Social $\mathcal{E}$ Political Thought, 19, 131-154.

Frith, C. D. (2007). The social brain? Philosophical Transactions of the Royal Society, B, 362, 671-678.

Glowacki, L., \& Lew-Levy, S. (2022). How small-scale societies achieve large-scale cooperation. Current Opinion in Psychology, 44, 44-48.

Graziano, M. (2013). Consciousness E The Social Brain. OUP.

Habermas, J. (1984). The Theory of Communicative Action, Volume I: Reason $\mathcal{E}$ the Rationalization of Society (translated by T. McCarthy). Beacon.

Habermas, J. (1989). The Structural Transformation of the Public Sphere (translated by T. Burger \& F. Lawrence). MIT Press.

Hallpike, C. R. (2020). A sceptical review of Bregman's HumanKind: A Hopeful History. New English Review.

Hans, V. P. (2007). Deliberation and dissent: 12 Angry Men versus the empirical reality of juries. Chicago-Kent Law Review, 82(2), 579-589.

Hansen, S., Berente, N., \& Lyytinen, K. (2009). Wikipedia, critical social theory, and the possibility of rational discourse. The Information Society, 25(1), 38-59.

Heintz, C., \& Scott-Phillips, T. (accepted). Expression unleashed: The evolutionary \& cognitive foundations of human communication. Behavioral $\mathcal{E}$ Brain Sciences.

Ho, M. K., MacGlashan, J., Littman, M. L., \& Cushman, F. (2017). Social is special: A normative framework for teaching with and learning from evaluative feedback. Cognition, 167, 91-106.

Hooper, P. L., Kaplan, H. S., \& Jaeggi, A. V. (2021). Gains to cooperation drive the evolution of egalitarianism. Nature Human Behaviour, 5, 847-856.

Humphrey N. K (1976). The social function of intellect. In: P. P. G. Bateson \& R. A. Hinde (Eds.), Growing Points in Ethology (pp. 303-317). CUP. 
Ignatieff, M. (2018). Introduction. In: M. Ignatieff \& S. Roch (Eds.), Rethinking Open Society: New Adversaries \& New Opportunities (pp. 1-16). CEU Press.

Jaeggi, A., \& Gurven, M. (2013). Natural cooperators: Food sharing in humans and other primates. Evolutionary Anthropology, 22(4), 186-195.

Keshmirian, A., Deroy, O., \& Bahrami, B. (2022). Many heads are more utilitarian than one. Cognition, 220, 104965.

Krasnow, M. M., Delton, A. W., Tooby, J. \& Cosmides, L. (2013). Meeting now suggests we will meet again: Implications for debates on the evolution of cooperation. Scientific Reports, 3, 1-8.

Landemore, H. (2013). Democractic Reason: Politics, Collective Intelligence, and the Rule of the Many. PUP.

Landemore, H. (2020). Open Democracy: Reinventing Popular Rule for the Twenty-First Century. PUP.

Longino, H. E. (2001). The Fate of Knowledge. PUP.

Mahr, J., \& Csibra, G. (2018). Why do we remember? The communicative function of episodic memory. Behavioral \& Brain Sciences, 41, e1.

McCullough, M. E. (2020). The Kindness of Strangers: How a Selfish Ape Invented a New Moral Code. Simon \& Schuster.

Meehl, P. E. (1967). Theory-testing in psychology and physics: A methodological paradox. Philosophy of Science, 34(2), 103-115.

Mercier, H., \& Claidière, N. (in press). Does discussion make crowds any wiser? Cognition.

Mercier, H., \& Landemore, H. (2012). Reasoning is for arguing: Understanding the successes and failures of deliberation. Political Psychology, 33(2), 243-258.

Mercier, H., \& Sperber, D. (2017). The Enigma of Reason. HUP.

Navajas, J., Niella, T., Garbulsky, G., Bahrami, B., \& Sigman, M. (2018). Aggregated knowledge from a small number of debates outperforms the wisdom of large crowds. Nature Human Behaviour, 2(2), 126-132.

Oakeshott, M. (1991). Rationalism in Politics \& Other Essays. Liberty Fund.

Ostrom, E. (1990). Governing The Commons: The Evolution of Institutions for Collective Action. CUP.

O’Malley, E., Farrell, D. M., \& Suiter, J. (2020). Does talking matter? A quasi-experiment assessing the impact of deliberation and information on opinion change. International Political Science Review, 41(3), 321-334.

Page, S. (2008). The Difference: How the Power of Diversity Creates Better Groups, Firms, Schools $\mathcal{E}$ Societies. PUP.

Pietraszewski, D. (2020). The evolution of leadership: Leadership and followership as a solution to the problem of creating and executing successful coordination and cooperation enterprises. The Leadership Quarterly, 31(2), 101299. 
Pigliucci, M., \& Boudry, M. (Eds.). (2013). Philosophy of Pseudoscience: Reconsidering the Demarcation Problem. UCP.

Popper, K. (1952). The Open Society \& Its Enemies (2nd edition). Routledge.

Popper, K. (1988). The open society and its enemies revisited. The Economist, 23, 19-22.

Runciman, D. (2018). Closed minds: The rise of conspiracy thinking. Times Literary Supplement, 6041, 26-28.

Scruton, R. (1980). The Meaning of Conservatism. Penguin.

Scruton, R. (2018). The open society from a conservative perspective. In: M. Ignatieff \& S. Roch (Eds.), Rethinking Open Society: New Adversaries \& New Opportunities (pp. 31-46). CEU Press.

Shi, F., Teplitskiy, M., Duede, E., \& Evans, J. A. (2019). The wisdom of polarized crowds. Nature Human Behaviour, 3(4), 329-336.

Singh, M., \& Glowacki, L. (under review). Human social organization during the Late Pleistocene: Beyond the nomadic-egalitarian model.

Singh, M., Wrangham, R., \& Glowacki, L. (2017). Self-interest and the design of rules. Human Nature, 28, 457-480.

Sperber, D., Clément, F., Heintz, C., Mascaro, O., Mercier, H., Origgi, G., \& Wilson, D. (2010). Epistemic vigilance. Mind \& Language, 25(4), 359-393.

Spiekermann, K. (2020). Why populists do well on social media. Global Justice: Theory Practice Rhetoric, 12(2), 50-71.

Stokes, G. (1995). Politics, epistemology and method: Karl Popper's conception of human nature. Political Studies, 43(1), 105-123.

Stokes, G. (2016). Popper and Habermas: Convergent arguments for a postmetaphysical universalism. In: J. Shearmur \& G. Stokes (Eds.) The Cambridge Companion to Popper (pp. 318-351). CUP.

Suiter, J. (2018). Deliberation in action: Ireland's abortion referendum. Political Insight, 9(3), 30-32.

Suiter, J., M Farrell, D., Harris, C., \& Murphy, P. (in press). Measuring epistemic deliberation on polarized issues: The case of abortion provision in Ireland. Political Studies Review.

Szegőfi, A., \& Heintz, C. (in press). Institutions of epistemic vigilance: The case of the press. Social Epistemology.

Tomasello, M. (2014). The ultra-social animal. European Journal of Social Psychology, 44(3), 187-194.

Tully, J. (2008). To think and act differently: Comparing critical ethos and critical theory. In: Public Philosophy in a New Key, Volume 1: Democracy \& Civic Freedom (pp. 71-132). CUP. van Reybrouck, D. (2016). Against Elections: The Case For Democracy. Bodley Head. 
von Rueden, C. (2020). Making and unmaking egalitarianism in small-scale human societies. Current Opinion in Psychology, 33, 167-171.

Weber, M. (2004). The Vocation Lectures. Hackett Publishing.

Wiessner, P. (2002). The vines of complexity: Egalitarian structures and the institutionalization of inequality among the Enga. Current Anthropology, 43(2), 233-269.

Williams, D. (2021). Socially adaptive belief. Mind E Language, 36(3), 333-354.

Woodburn, J. (1982). Egalitarian societies. Man, 17(3), 431-451.

Ziman, J. M. (1968). Public Knowledge: An Essay Concerning the Social Dimension of Science. CUP. 